\title{
Multiple-sulfur isotope effects during photolysis of carbonyl sulfide
}

\author{
Y. Lin $^{1,2}$, M. S. Sim ${ }^{1}$, and S. Ono ${ }^{1}$ \\ ${ }^{1}$ Department of Earth, Atmospheric and Planetary Sciences, Massachusetts Institute of Technology, 77 Massachusetts \\ Avenue, Cambridge, MA 02139, USA \\ ${ }^{2}$ State Key Laboratory for Mineral Deposits Research, School of Earth Sciences and Engineering, Nanjing University, \\ Nanjing, Jiangsu 210093, China
}

Received: 23 April 2011 - Published in Atmos. Chem. Phys. Discuss.: 9 May 2011

Revised: 26 September 2011 - Accepted: 28 September 2011 - Published: 14 October 2011

\begin{abstract}
Laboratory experiments were carried out to determine sulfur isotope effects during ultraviolet photolysis of carbonyl sulfide (OCS) to carbon monoxide (CO) and elemental sulfur $\left(\mathrm{S}^{0}\right)$. The OCS gas at 3.7 to $501 \mathrm{mbar}$ was irradiated with or without a $\mathrm{N}_{2}$ bath gas using a 150 $\mathrm{W}$ Xe arc lamp. Sulfur isotope ratios for the product $\mathrm{S}^{0}$ and residual OCS were analyzed by an isotope ratio mass-spectrometer with $\mathrm{SF}_{6}$ as the analyte gas. The isotope fractionation after correction for the reservoir effects is $-6.8 \%$ for the ratio ${ }^{34} \mathrm{~S} /{ }^{32} \mathrm{~S}$, where product $\mathrm{S}^{0}$ is depleted in heavy isotopes. The magnitude of the overall isotope effect is not sensitive to the addition of $\mathrm{N}_{2}$ but increases to $-9.5 \%$ when radiation of $\lambda>285 \mathrm{~nm}$ is used. The measured isotope effect reflects that of photolysis as well as the subsequent sulfur abstraction (from OCS) reaction. The magnitude of isotope effects for the abstraction reaction is estimated by transition state theory to be between -18.9 and $-3.1 \%$ o for ${ }^{34} \mathrm{~S}$ which gives the photolysis isotope effect as -10.5 to $+5.3 \%$. The observed triple isotope coefficients are $\ln \left(\delta^{33} \mathrm{~S}+1\right) / \ln \left(\delta^{34} \mathrm{~S}+1\right)=0.534 \pm 0.005$ and $\ln \left(\delta^{36} \mathrm{~S}+1\right) / \ln \left(\delta^{34} \mathrm{~S}+1\right)=1.980 \pm 0.021$. These values differ from canonical values for mass-dependent fractionation of 0.515 and 1.90 , respectively. The result demonstrates that the OCS photolysis does not produce large isotope effects of more than about $10 \%$ for ${ }^{34} \mathrm{~S} /{ }^{32} \mathrm{~S}$, and can be the major source of background stratospheric sulfate aerosol (SSA) during volcanic quiescence.
\end{abstract}

Correspondence to: Y. Lin

(yinglin@nju.edu.cn)

\section{Introduction}

Carbonyl sulfide (OCS) accounts for more than $80 \%$ of gasphase sulfur above $8 \mathrm{~km}$ as the most resistant reduced sulfur species to oxidation in the troposphere (e.g. Farwell et al., 1995; Turco et al., 1980; Khalil and Rasmussen, 1984; Crutzen, 1976). The low solubility and long atmospheric lifetime (about $4 \mathrm{yr}$ ) with respect to tropospheric chemistry and photolysis enables a significant fraction of OCS to reach the stratosphere (Blake et al., 2008; Pandis et al., 1995; Chin and Davis, 1995; Barkley et al., 2008). OCS exhibits a continuum ultraviolet (UV) absorption spectrum from 200 to $260 \mathrm{~nm}$. Upon UV irradiation in this wavelength range, OCS photodissociates to carbon monoxide and elemental sulfur $\left(S^{0}\right)$ with total quantum yield $(\Phi)$ close to 1 (Sidhu et al., 1966; Rudolph and Inn, 1981):

$\mathrm{OCS}+h v \rightarrow \mathrm{S}+\mathrm{CO}$

The sulfur atom is oxidized by $\mathrm{OH} / \mathrm{O}_{3} / \mathrm{O}_{2}$ to $\mathrm{SO}_{2}$ and forms sulfate, and is thought to contribute to the stratospheric sulfate aerosol layer (Junge layer) (Junge et al., 1961; Crutzen, 1976; Pitari et al., 2002). The stratospheric sulfate aerosol (SSA) layer at $17-30 \mathrm{~km}$, with lifetime of 3-4 yr, affects the atmospheric radiation balance and catalyzes heterogeneous reactions that recycle the inert halogen species related to the ozone budget (e.g. Junge et al., 1961; Danielache et al., 2008; Crutzen, 1976; Turco et al., 1980). Understanding the sources and sinks for SSA is of societal importance because artificial formation of SSA is suggested as one potential approach to manage solar radiation in order to mitigate the global warming by greenhouse gases (e.g. Robock et al., 2008). The other significant sources of SSA are oxidation of $\mathrm{SO}_{2}$ transported upward from the lower troposphere by diffusion (Crutzen, 1976), uplifted tropospheric $\mathrm{H}_{2} \mathrm{SO}_{4}$ (Pitari et al., 2002), and direct stratospheric injection of $\mathrm{SO}_{2}$

Published by Copernicus Publications on behalf of the European Geosciences Union. 
by explosive volcanism (Castleman et al., 1973; Pyle et al., 1996). During volcanic quiescence, $\mathrm{SO}_{2}$ and OCS were assessed to contribute about equally to the stratospheric sulfur budget, but significant uncertainty remains (e.g. SPARC, 2006).

The studies of sulfur isotope $\left({ }^{32} S /{ }^{33} S /{ }^{34} S /{ }^{36} S\right)$ ratios may provide important constraints on the sources of SSA if source isotope signatures and isotope effects during chemical conversions are characterized. Leung et al. (2002) and Colussi et al. (2004) suggested relatively large isotope effects of $(73.8 \pm 8.6) \% o$ and $(67 \pm 7) \%$, respectively, for the ${ }^{34} \mathrm{~S} /{ }^{32} \mathrm{~S}$ fractionation during the UV photolysis of OCS. These values suggest SSA would be highly enriched in ${ }^{34} \mathrm{~S}$ if OCS photolysis were the main source for the SSA. Since the background SSA yields only small delta values of $(2.6 \pm 0.3) \%$ o $\left(\delta^{34} \mathrm{~S}_{\mathrm{CDT}}\right)$ (Castleman et al., 1973), it was concluded that the contribution of OCS to SSA is either negligible or must be balanced by severely ${ }^{34} \mathrm{~S}$-depleted species, such as sulfate produced from $\mathrm{SO}_{2}$ (Leung et al., 2002; Colussi et al., 2004). Recent calculation employing wavepacket dynamics, however, showed that sulfur isotope substitution has little effect on the UV cross sections of OCS, and discounted the large isotope effect suggested by Colussi et al. (2004) (Danielache et al., 2009). Therefore, one objective of this study is to measure the isotope fractionation during OCS photolysis reaction by simple laboratory experiments.

Our study also focuses on the rare and non-conventional isotopes of sulfur $\left({ }^{33} \mathrm{~S}\right.$ and $\left.{ }^{36} \mathrm{~S}\right)$ because certain gas phase reactions, $\mathrm{SO}_{2}$ photolysis and $\mathrm{CS}_{2}$ photopolymerization, are known to produce non-mass-dependent isotope effects (Farquhar et al., 2001; Colman et al., 1996; Zmolek et al., 1999). Non-mass-dependent isotope effect refers to an isotope effect that does not follow conventional mass-scaling law. That is, the isotope fractionation for the ratio ${ }^{33} \mathrm{~S} /{ }^{32} \mathrm{~S}$ is about a half of ${ }^{34} \mathrm{~S} /{ }^{32} \mathrm{~S}$ and ${ }^{36} \mathrm{~S} /{ }^{32} \mathrm{~S}$ is about twice as much as that of ${ }^{34} \mathrm{~S} /{ }^{32} \mathrm{~S}$. More precisely, $\ln \left({ }^{33} \alpha\right)={ }^{33} \theta \ln \left({ }^{34} \alpha\right)$ and $\ln \left({ }^{36} \alpha\right)={ }^{36} \theta \ln \left({ }^{34} \alpha\right)$, where ${ }^{x} \alpha$ is the isotope fractionation factor for the ratio ${ }^{x} \mathrm{~S} /{ }^{32} \mathrm{~S}$, where ${ }^{33} \theta$ and ${ }^{36} \theta$ are 0.515 and 1.90, respectively (Hulston and Thode, 1965). The signatures of S non-mass-dependent fractionation have been found exclusively in Archean rocks (e.g. Farquhar et al., 2000; Ono et al., 2003) and SSA deposited in polar ice after major volcanic events (Savarino et al., 2003; Baroni et al., 2007). Although photolysis of $\mathrm{SO}_{2}$ is thought to be the source reaction for these $\mathrm{S}$ non-mass-dependent signatures, the physical origin of this unconventional sulfur isotope effect is poorly understood (Farquhar et al., 2001). Given that OCS could have been an important atmospheric sulfur gas in the Archean (Ueno et al., 2009) as well as an important contributor for SSA, it is important to test whether the isotope effect during the photolysis of OCS follows a mass-dependent law.

Therefore, this study has three objectives. The first is to fill the gap in isotope fractionation factor during OCS photolysis by carrying out laboratory photochemical experiments, the second is to test if OCS photolysis follows the conventional mass-dependent law by determining multiple-sulfur isotope fractionation factors, and the third is to test whether OCS contributes to SSA.

\section{Experimental set up}

A 150 watt Xenon arc lamp (Newport Model 6254) with lamp housing (Newport Model 67005) was used as a light source. The Xenon arc lamp has irradiance of about $1.5 \mathrm{~mW} \mathrm{~m}^{-2} \mathrm{~nm}^{-1}$ at $200 \mathrm{~nm}$, increasing to $10.5 \mathrm{~mW} \mathrm{~m}^{-2} \mathrm{~nm}^{-1}$ at $300 \mathrm{~nm}$. The photochemical reaction cell is a 30-cm-long, 48-mm-ID glass cylinder equipped with optical grade quartz windows (Aceglass Model 789435). The transmittance of the window is $40 \%$ at $200 \mathrm{~nm}$, increasing to $90 \%$ at $300 \mathrm{~nm}$. For wavelength $\lambda>285 \mathrm{~nm}$ experiments, an Oriel colored glass filter (Newport Model 59423) was used. Commercial carbonyl sulfide ( $\geq 97.5 \%$ pure, Sigma Aldrich) was used for this study as the reactant. The gas chromatography (1/8-inch-OD column packed with SupelcoChromosil 310) analysis by a TCD detector showed that most impurity is composed of $\mathrm{CO}_{2}(2.5 \%)$.

The OCS was introduced to the photochemical cell through a glass vacuum line. Pressures for the initial OCS, residual OCS, and product $\mathrm{CO}$ were monitored by a capacitance manometer. In all experiments, yellowish elemental sulfur $\left(S^{0}\right)$ condensed on the inner surfaces of the windows and the photochemical cell. After photolysis, residual OCS was collected at liquid nitrogen temperature. The OCS (initial or residual) was hydrolyzed in alkaline zinc solution $\left(0.14 \mathrm{moll}^{-1}\right.$ zinc acetate in $\left.2 \mathrm{moll}^{-1} \mathrm{NaOH}\right)$, and sulfur was precipitated as $\mathrm{ZnS}$. The $\mathrm{ZnS}$ was converted to $\mathrm{Ag}_{2} \mathrm{~S}$ by $0.1 \mathrm{moll}^{-1} \mathrm{AgNO}_{3}$ after neutralizing with zinc acetate solution. The $S^{0}$ precipitated inside the photochemical cell was dissolved in about $50 \mathrm{ml}$ dichloromethane (DCM). After evaporating DCM, $\mathrm{S}^{0}$ was reduced by chromium chloride following Canfield et al. (1986), and was precipitated as $\mathrm{Ag}_{2} \mathrm{~S}$.

The isotope ratio analysis was carried out in the stable isotope laboratory at MIT with a procedure similar to the one described in Ono et al. (2006). Approximately $2 \mathrm{mg}$ of silver sulfide was reacted with elemental fluorine (about $70 \mathrm{mbar}$ ) for over $6 \mathrm{~h}$ at $300^{\circ} \mathrm{C}$. The product $\mathrm{SF}_{6}$ was purified by a preparative gas chromatography equipped with a packed column of Molesieve 5A and Hayesep Q. Isotope ratios were analyzed by an isotope ratio mass spectrometer (Thermoelectron MAT 253) by measuring ions ${ }^{32} \mathrm{SF}_{5}^{+},{ }^{33} \mathrm{SF}_{5}^{+},{ }^{34} \mathrm{SF}_{5}^{+}$, and ${ }^{36} \mathrm{SF}_{5}^{+}$. Six replicated analyses of OCS, sampled as initial OCS for different experiments, yield $2 \sigma$ standard deviations of $0.26,0.53$, and $1.05 \%$ o for $\delta^{33} \mathrm{~S}, \delta^{34} \mathrm{~S}$, and $\delta^{36} \mathrm{~S}$, respectively. These numbers represent errors for gas handling, wet chemistry (hydration and precipitation), fluorination, and mass spectrometer analysis. Errors in $\delta^{33} \mathrm{~S}, \delta^{34} \mathrm{~S}$, and $\delta^{36} \mathrm{~S}$ are mass-dependently correlated. 


\section{Results}

Sulfur isotope ratios are reported by conventional delta notation:

$\delta^{x} \mathrm{~S}=\frac{{ }^{x} \mathrm{R}_{\text {sample }}}{{ }^{x} \mathrm{R}_{\text {reference }}}-1$

where ${ }^{x} \mathrm{R}_{\text {sample }}$ is the isotope ratio $\left({ }^{x} \mathrm{~S} /{ }^{32} \mathrm{~S}\right.$, where $x=33,34$, or 36) of product $S^{0}$ or residual OCS and ${ }^{x} R_{\text {reference }}$ is that of initial OCS, and multiply by 1000 to be represented as per mil (\%o).

Results for 12 UV photolysis of OCS are shown in Table 1 . Residual OCS is enriched in ${ }^{34} \mathrm{~S}$ up to $4.43 \%$ except for 11-28, which is taken as an experimental error due to low $\mathrm{S}^{0}$ yield for the long-duration run. The photolysis product $\mathrm{S}^{0}$ is depleted in $\delta^{34} \mathrm{~S}$ by 2.24 to $6.72 \%$ with respect to initial OCS. Because isotope ratios of reactant OCS change during photolysis, the fractionation due to the photodissociation is calculated using an approximated formula of Rayleigh distillation (Mariotti et al., 1981):

${ }^{34} \varepsilon=\frac{f-1}{f \ln (f)} \delta^{34} \mathrm{~S}_{\mathrm{S}}$

where, ${ }^{34} \varepsilon, \delta^{34} \mathrm{~S}_{\mathrm{S}}$, and $f$ are the isotope fractionation, isotopic composition of $S^{0}$ at the end of the run, and the fraction of residual OCS, respectively. In this definition, a negative value of $\varepsilon$ indicates that the product $S^{0}$ is depleted in ${ }^{34} S$. The value for $f$ is derived from $S^{0}$ yield and initial OCS gas pressure or from isotope mass balance for runs where isotope compositions for both residual OCS and $\mathrm{S}^{0}$ are measured. The two ${ }^{34} \varepsilon$ estimates are largely consistent, in particular, in runs 10-02, 10-03, and 11-11 (Table 1 ). The two $f$ values differ for the run 11-05, likely due to error in pressure measurements. The consistency between the ${ }^{34} \varepsilon$ (and also $f$ ) values calculated from yield and those from mass balance indicates insignificant isotopic fractionation during analytical procedures.

For pure OCS experiments with $\lambda>200 \mathrm{~nm}$, isotope effects $\left({ }^{34} \varepsilon\right)$ of $(-6.8 \pm 0.2) \%$ are derived for the best set of experiments (10-02 and 11-11). These two results represent the low $\mathrm{S}^{0}$ yield (i.e. small reservoir size correction), and consistent $f$ values. Addition of $\mathrm{N}_{2}$ (experiments 10$19,11-10$, and $11-12$ ) yields ${ }^{34} \varepsilon$ of -6.8 to $-5.3 \%$, showing that the quenching of $\mathrm{S}\left({ }^{1} \mathrm{D}\right)$ by $\mathrm{N}_{2}$ has little or no effect on the isotope fractionation. The experiment 11-28 with $\lambda>285 \mathrm{~nm}$ radiation yields a slightly larger isotope effect of $-9.5 \%$.

When all data are plotted in $\ln \left(\delta^{33} \mathrm{~S}+1\right)$ vs. $\ln \left(\delta^{34} \mathrm{~S}+1\right)$ and $\ln \left(\delta^{36} \mathrm{~S}+1\right)$ vs. $\ln \left(\delta^{34} \mathrm{~S}+1\right)$ diagrams, the least square fit slopes are $0.534 \pm 0.005$ and $1.980 \pm 0.021$, respectively (Fig. 1). The log scale is used here to take into account the power law relationship of mass-dependent fractionation (e.g. Luz and Barkan, 2005). The standard errors are derived from linear regression and depend on residuals of the fits and degree-of-freedom $(d f)$ of the residuals, both derived by ANOVA (Analysis of Variance) in statistical program SPSS.
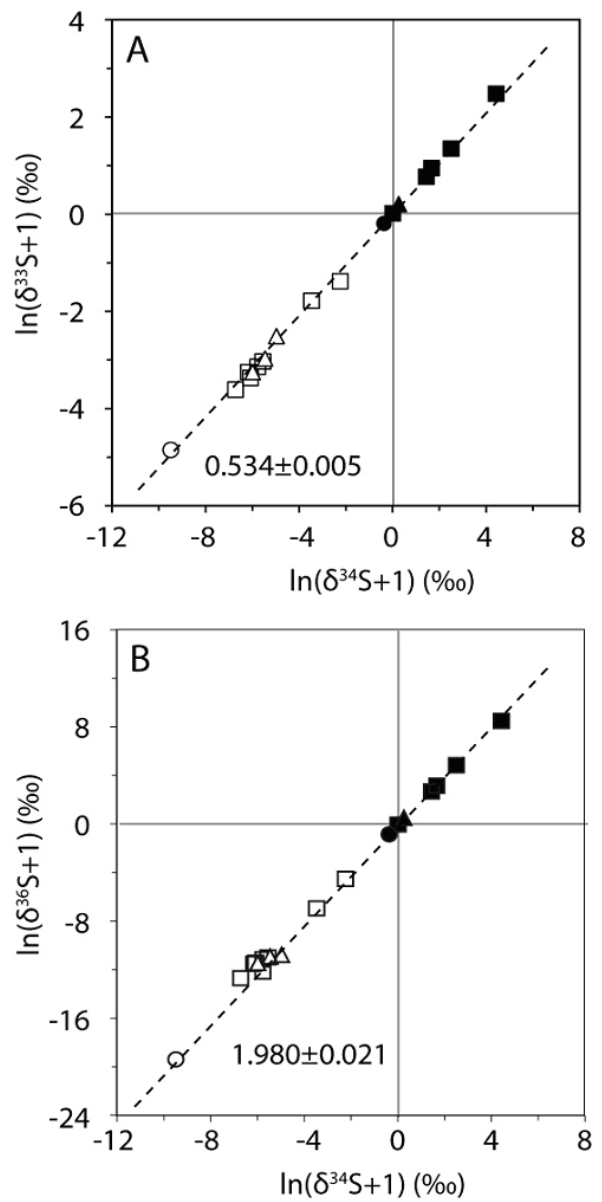

Fig. 1. Sulfur isotopic compositions of residual OCS (filled symbols) and product $\mathrm{S}^{0}$ (open symbols) relative to initial OCS after photolysis of OCS. Square, triangle, and circle symbols are for pure OCS, OCS with $\mathrm{N}_{2}$, and OCS with $\lambda>285 \mathrm{~nm}$ photolysis experiments, respectively.

\section{Discussion}

\subsection{Sulfur isotope effects for laboratory OCS photolysis experiments}

For laboratory OCS photochemistry experiments employed in this study, photodissociation of OCS (Reaction R1) is followed by sulfur abstraction from OCS (Reaction R2) (Basco and Pearson, 1967; Breckenridge and Taube, 1970; Wiebe et al., 1964; Zhao et al., 1995):

$\mathrm{OCS}+\mathrm{S} \rightarrow \mathrm{S}_{2}+\mathrm{CO}$

The product $S_{2}$ follows complex series of recombination and potentially photolysis before deposition on the wall of the photochemical cell. We have constructed a simple photochemical model including various $S_{n}$ recombination and photolysis reactions as well as wall loss. The main sink of the product $S_{2}$ is expected to be a recombination, such as 
Table 1. Results for OCS photolysis experiments. Delta values are relative to initial OCS.

\begin{tabular}{|c|c|c|c|c|c|c|c|c|c|c|c|c|c|c|c|}
\hline \multirow[t]{2}{*}{ Run-ID } & \multirow{2}{*}{$\begin{array}{r}\text { OCS } \\
\text { (mbar) }\end{array}$} & \multirow{2}{*}{$\begin{array}{l}\text { Time } \\
(\min )\end{array}$} & \multirow{2}{*}{$\begin{array}{r}\mathrm{N}_{2} \\
\text { (mbar) }\end{array}$} & \multirow{2}{*}{$\begin{array}{r}\lambda \\
(\mathrm{nm})\end{array}$} & \multirow{2}{*}{$\begin{array}{r}\mathrm{S}^{0} \text { Yield } \\
(\mu \mathrm{mol})\end{array}$} & \multicolumn{3}{|c|}{$\mathrm{S}^{0}$} & \multicolumn{3}{|c|}{ Residual OCS } & \multicolumn{2}{|l|}{$f$} & \multicolumn{2}{|c|}{${ }^{34}{ }_{\varepsilon}(\% o)$} \\
\hline & & & & & & $\delta^{33} \mathrm{~S}$ & $\delta^{34} \mathrm{~S}$ & $\delta^{36} \mathrm{~S}$ & $\delta^{33} \mathrm{~S}$ & $\delta^{34} \mathrm{~S}$ & $\delta^{36} \mathrm{~S}$ & Yield $^{\mathrm{a}}$ & $\mathrm{MB}^{\mathrm{b}}$ & Yield $^{\mathrm{a}}$ & $\mathrm{MB}^{\mathrm{b}}$ \\
\hline $07-25$ & 22.5 & 60 & & & n.d. & -3.25 & -6.17 & -11.51 & 0.77 & 1.44 & 2.67 & & 0.81 & & -6.9 \\
\hline $09-17$ & 24.5 & 180 & & & 271.4 & -1.78 & -3.47 & -6.95 & & & & 0.53 & & -4.8 & \\
\hline $10-02$ & 11.5 & 60 & & & 65.2 & -3.37 & -6.08 & -11.43 & 0.95 & 1.67 & 3.15 & 0.76 & 0.78 & -7.0 & -6.9 \\
\hline $10-03$ & 6.9 & 60 & & & 66.6 & -3.14 & -5.77 & -11.15 & 2.48 & 4.43 & 8.49 & 0.59 & 0.57 & -7.6 & -7.7 \\
\hline $10-23$ & 85.3 & 60 & & & 78.4 & -3.14 & -5.77 & -12.17 & & & & 0.96 & & -5.9 & \\
\hline $10-29$ & 3.9 & 60 & & & 66.9 & -1.38 & -2.24 & -4.52 & & & & 0.26 & & -4.7 & \\
\hline $11-05$ & 4.1 & 30 & & & 6.8 & -3.03 & -5.55 & -10.99 & 1.35 & 2.5 & 4.84 & 0.93 & 0.69 & -5.8 & -6.7 \\
\hline $11-11$ & 25.3 & 10 & & & 21.3 & -3.61 & -6.72 & -12.7 & 0.02 & 0.01 & -0.05 & 0.96 & 1.00 & -6.9 & -6.7 \\
\hline $10-19$ & 19.5 & 60 & 53.3 & & 50.3 & -2.51 & -4.97 & -10.79 & & & & 0.89 & & -5.3 & \\
\hline $11-10$ & 26.1 & 60 & 401 & & 94.8 & -2.97 & -5.46 & -10.93 & & & & 0.85 & & -5.9 & \\
\hline $11-12$ & 3.7 & 30 & 405 & & 18.9 & -3.25 & -5.99 & -11.46 & 0.21 & 0.26 & 0.5 & 0.78 & 0.96 & -6.8 & -6.1 \\
\hline $11-28$ & 501 & $48 \mathrm{hr}$ & & $>285$ & 68.9 & -4.85 & -9.49 & -19.39 & -0.19 & -0.37 & -0.85 & 0.99 & 1.04 & -9.5 & -9.3 \\
\hline
\end{tabular}

${ }^{a}$ Residual OCS derived from $\mathrm{S}^{0}$ yield.

$\mathrm{b}$ That derived from isotope mass balance.

$\left(2 S_{2}+M \rightarrow S_{4}+M\right)$. The $S_{2}$ number density does not reach high enough so that the photolysis of $\mathrm{S}_{2}\left(\mathrm{~S}_{2}+h v \rightarrow 2 \mathrm{~S}\right)$ does not become a significant $(<0.1 \%)$ source of $\mathrm{S}$. Detailed description of the model is available in the Supplement.

Assuming intermediate steady state condition for atomic $\mathrm{S}$, if the rates of both Reactions (R1) and (R2) are sensitive to sulfur isotope substitution, the measured isotope effects would be the average of the isotope effects associated with the two reactions. For ${ }^{34} \mathrm{~S}$, that is:

${ }^{34} \varepsilon=1 / 2\left({ }^{34} \varepsilon_{1}+{ }^{34} \varepsilon_{2}\right)$

where ${ }^{34} \varepsilon_{1}$ and ${ }^{34} \varepsilon_{2}$ are the isotope fractionations due to photolysis (Reaction R1) and sulfur abstraction Reaction (R2), respectively. The statistical weight reflects two sulfur atoms in $S_{2}$. The derivation of Eq. (3) is available in the Supplement. Under the assumption, mass of the atomic sulfur in the Reaction (R2) (i.e. OCS $+{ }^{32} \mathrm{~S}$ versus $\mathrm{OCS}+{ }^{34} \mathrm{~S}$ ) does not produce isotope effects in the overall product. Thus, ${ }^{34} \varepsilon_{2}$ represents the difference in the reaction rates between $\mathrm{OC}^{34} \mathrm{~S}+\mathrm{S}$ and $\mathrm{OC}^{32} \mathrm{~S}+\mathrm{S}$. In order to gain constraints on the isotope effect for UV photolysis, we will first estimate the isotope effect during sulfur abstraction reaction.

\subsection{Sulfur isotopic effects during sulfur abstraction reaction}

The OCS photolysis (Reaction R1) produces S in both singlet and triplet states. The isotope effect associated with the sulfur abstraction reaction $\left({ }^{34} \varepsilon_{2}\right)$ may depend on the spin state of $\mathrm{S}$ atom since the reaction follows either a singlet or triplet potential energy surface (Lu et al., 2006). Three sets of experiments were designed to assess the different $S_{2}$ formation channels to elucidate the systematics of isotope fractionation.

In experiments with $\lambda>200 \mathrm{~nm}$, without $\mathrm{N}_{2}$ bath gas, the reactions are:

$\mathrm{OCS}+h v \rightarrow \mathrm{CO}+\mathrm{S}\left({ }^{1} \mathrm{D}\right)$
$\mathrm{OCS}+h v \rightarrow \mathrm{CO}+\mathrm{S}\left({ }^{3} \mathrm{P}\right)$

$\mathrm{S}\left({ }^{1} \mathrm{D}\right)+\mathrm{OCS} \rightarrow \mathrm{CO}+\mathrm{S}_{2}$

$\mathrm{S}\left({ }^{3} \mathrm{P}\right)+\mathrm{OCS} \rightarrow \mathrm{CO}+\mathrm{S}_{2}$

$\mathrm{S}\left({ }^{1} \mathrm{D}\right)+\mathrm{OCS} \rightarrow \mathrm{OCS}+\mathrm{S}\left({ }^{3} \mathrm{P}\right)$

During photolysis (R1), atomic sulfur is produced predominantly in $S\left({ }^{1} \mathrm{D}\right)$ electronic state $\left(\Phi_{1 \mathrm{a}}=0.74\right)$ because production of $\mathrm{S}\left({ }^{3} \mathrm{P}\right)$ is spin forbidden (Okabe, 1978; Sidhu et al., 1966; Breckenridge and Taube, 1970). Pseudofirst-order rate constants for Reactions (R2a), (R2b), and (R3) were estimated to be $5 \times 10^{-11}, 2.7 \times 10^{-15}$, and $15 \times 10^{-11} \mathrm{~cm}^{3} \mathrm{~s}^{-1}$, respectively (Zhao et al., 1995; Lu et al., 2006). Given these rate constants, approximately one fifth of $S_{2}$ is formed through abstraction reaction with $S\left({ }^{1} D\right)$ and the rest is from $S\left({ }^{3} \mathrm{P}\right)$ channel.

The addition of inert gas $\left(\mathrm{N}_{2}\right)$ in the second set of experiments would quench $\mathrm{S}\left({ }^{1} \mathrm{D}\right)$ :

$\mathrm{S}\left({ }^{1} \mathrm{D}\right)+\mathrm{N}_{2} \rightarrow \mathrm{N}_{2}+\mathrm{S}\left({ }^{3} \mathrm{P}\right)$

Rate constant for the Reaction (R4) is estimated to be $8 \times 10^{-11} \mathrm{~cm}^{3} \mathrm{~s}^{-1}$ (Zhao et al., 1995). Under the experimental conditions (53.3 to 400 mbar $\mathrm{N}_{2}$ ), the production of $\mathrm{S}_{2}$ is exclusively from $S\left({ }^{3} \mathrm{P}\right)$ channel (Reaction $\mathrm{R} 2 \mathrm{~b}$ ). The $\mathrm{S}_{2}$ recombination reaction:

$2 \mathrm{~S}\left({ }^{3} \mathrm{P}\right)+\mathrm{N}_{2} \rightarrow \mathrm{N}_{2}+\mathrm{S}_{2}$

is slow (second-order rate constant is about $10^{-33} \mathrm{~cm}^{6} \mathrm{~s}^{-1}$ ) (Du et al., 2008) and is only relevant if a high power UV source is used (Breckenridge and Taube, 1970). Because dissociation threshold through $\mathrm{S}\left({ }^{1} \mathrm{D}\right)$ channel (R1a) is $(4.26 \pm 0.1) \mathrm{eV}$ or $(291 \pm 7) \mathrm{nm}$ (Suzuki et al., 1998), photolysis of OCS with $\lambda>285 \mathrm{~nm}$ produces $S^{0}$ exclusively in the triplet state (Reaction R1b). 
Table 2. Kinetic isotope effects for sulfur abstraction reactions estimated by the transition state theory.

\begin{tabular}{lrrrrr}
\hline Reaction & ${ }^{33} \varepsilon_{2}$ & ${ }^{34} \varepsilon_{2}$ & ${ }^{36} \varepsilon_{2}$ & ${ }^{33} \theta$ & ${ }^{36} \theta$ \\
\hline $\mathrm{OC}^{x} \mathrm{~S}+\mathrm{S} \rightarrow \mathrm{TS} 1 \rightarrow \mathrm{CO}+{ }^{x} \mathrm{SS}$ & -9.76 & -18.94 & -35.86 & 0.5131 & 1.910 \\
$\mathrm{OC}^{x} \mathrm{~S}+\mathrm{S} \rightarrow \mathrm{TS} 2 \rightarrow \mathrm{CO}+{ }^{x} \mathrm{SS}$ & -1.60 & -3.10 & -5.88 & 0.5144 & 1.900 \\
\hline
\end{tabular}

The experimental results show that addition of $\mathrm{N}_{2}$ does not significantly affect the overall isotope effect during OCS photolysis; ${ }^{34} \varepsilon$ is $-6.8 \%$ for pure OCS photolysis with $\lambda>200 \mathrm{~nm}$ versus -6.8 to $-5.3 \%$ for OCS photolysis with addition of $\mathrm{N}_{2}$ (Table 1). These similar ranges of isotope enrichments suggest that spin states have little effect on the isotope fractionation for the abstraction reaction. It will be discussed in the next section that the relatively larger magnitude isotope effect of $-9.5 \%$ ofor the photolysis with $\lambda>285 \mathrm{~nm}$, is likely due to photolysis itself rather than due to spin chemistry.

The isotope effect for sulfur abstraction reaction $\left({ }^{34} \varepsilon_{2}\right)$ is estimated by applying transition state theory (Van Hook, 1970; Tanaka et al., 1996). Lu et al. (2006) showed a number of possible transition states for the atomic $S$ abstraction Reactions (R2a and R2b). We used two of their transition states (TS1 and TS2) as representative transition state structures. The transition structure TS1 represents the main channel for the abstraction reaction, where atomic $S$ is attached to $\mathrm{S}$ in OCS forming a bent OC-S-S molecule. The transition state, TS2, is a minor channel but two $\mathrm{S}$ are attached to carbon forming a triangular O-C-S 2 molecule ( $\mathrm{Lu}$ et al., 2006). Vibrational frequencies for the ground state OCS and two transition states are calculated for four sulfur isotopologues at B3LYP/6-311+G(3df) level with Gaussian03. The estimated frequencies for OCS are scaled by $0.9793,0.9705$, and 0.9638 for bending, CS stretching, and OC stretching vibrational modes, respectively, to match experimental frequencies by Masukidi et al. (1992). Frequencies for TS1 and TS2 are estimated by using the geometry reported by Lu et al. (2006). The calculated vibrational frequencies with reported geometry reproduce reported vibrational frequencies at $\pm 0.3 \%$ for TS 2 but are different by $7 \%$ for TS 1 . The ${ }^{34} \varepsilon_{2}$ are estimated to be $-18.9 \%$ and $-3.1 \%$ for abstraction reaction via TS1 and TS2, respectively (Table 2). The calculated isotope effects are mass-dependent with ${ }^{33} \theta$ and ${ }^{36} \theta$ values of $0.5138 \pm 0.0006$ and $1.905 \pm 0.005$, respectively (Table 2).

Photochemical experiments using doubly isotope substituted carbonyl sulfide $\left({ }^{18} \mathrm{OC}^{34} \mathrm{~S}\right)$ show small degree of isotope exchange through atomic sulfur (Breckenridge and Taube, 1970):

$\mathrm{OC}^{32} \mathrm{~S}+{ }^{34} \mathrm{~S} \rightleftharpoons \mathrm{OC}^{34} \mathrm{~S}+{ }^{32} \mathrm{~S}$

Using the conventional formula (Bigeleisen and Mayer, 1947) and the estimated vibrational frequencies for OCS, the equilibrium constant for the Reaction (R6) is estimated to be 1.0175. Thus, isotope exchange Reaction (R6), when completed, $\mathrm{S}$ would be $-17.2 \%$ depleted with respect to OCS in ${ }^{34} \mathrm{~S}$. The extent of isotope exchange, however, is minor and is approximately $6 \%$ with respect to the photolysis yield (Breckenridge and Taube, 1970). Following the formula by Ohmoto and Lasaga (1982), the isotope exchange of about $6 \%$ may contribute at most $0.7 \%$ additional decrease in ${ }^{34} \varepsilon_{2}$; exact magnitude depends upon the initial isotopic compositions. Because the effect is small, the isotope exchange Reaction (R6) is not taken into account for the further analysis because the magnitude of the effect is small compared to that of photolysis and abstraction reactions.

With average ${ }^{34} \varepsilon$ values of $-6.8 \%$, using Eq. (3), isotope effects due to photolysis $\left({ }^{34} \varepsilon_{1}\right)$ are estimated to be $+5.3 \%$ o if transition structure TS1 is assumed (i.e. ${ }^{34} \varepsilon_{2}=-18.9 \%$ ) and $-10.5 \%$ if transition structure TS2 is assumed (i.e. ${ }^{34} \varepsilon_{2}=-3.1 \%$ ). Although the results do not constrain the sign of the ${ }^{34} \varepsilon_{1}$, our experimental data demonstrate that OCS photolysis is not likely a source of large (about $+67 \%$ ) isotope effect as previously suggested by Colussi et al. (2004).

\subsection{Comparison to the ZPE-shift model}

In order to compare our experimental results to available model of photolysis isotope effect, the ZPE-shift method of Miller and Yung (2000) was applied for OCS photolysis under the condition of the experiments. The ZPE-shift model is a simple and crude model. Laboratory cross section measurement for $\mathrm{N}_{2} \mathrm{O}$, for example, demonstrates, the ZPE-shift model only qualitatively describes the effect of isotope substitution (von Hessberg et al., 2004). In the later section, we discuss the comparison of our experimental results to a detailed model calculation using wavepacket dynamics for OCS photoexciation by Danielache et al. (2009).

Sulfur isotope effects for photolysis can be estimated from ZPE-shift method of Miller and Yung (2000) for the condition applied for the experiments (Colussi et al., 2004; Danielache et al., 2009). For a given experimental pressure, the isotopologue specific photodissociation rate constant is a function of the path length $(z)$ and wavelength $(\lambda)$ :

$$
{ }^{x} J(\lambda, z)={ }^{x} \Phi(\lambda)^{x} \sigma(\lambda) F_{0}(\lambda) e^{-\sigma_{\mathrm{OCS}} m z}
$$

where, $x$ represents each isotope (i.e. $x=32,33,34$, or 36 ), $\Phi$ is the photolysis quantum yield (assumed to be unity), $\sigma$ is the absorption cross section, and $F_{0}$, is a photon flux at the 
photocell window (i.e. at optical depth $z=0$ ). The last term is to correct opacity by the OCS between the light source and the given optical depth $(z), \sigma_{\mathrm{OCS}}$ and $m$ are the cross section of OCS and number density of total OCS (all isotopologues), respectively.

Absorption cross sections for minor isotopologues, $\mathrm{OC}^{33} \mathrm{~S}, \mathrm{OC}^{34} \mathrm{~S}$, and $\mathrm{OC}^{36} \mathrm{~S}$ can be estimated by blue-shifting $\mathrm{OC}^{32} \mathrm{~S}$ cross section following ZPE-shift method of Miller and Yung (2000):

${ }^{x} \sigma(E+\Delta \mathrm{ZPE})={ }^{32} \sigma(E)$

where $E$ is the photon energy and $\triangle \mathrm{ZPE}$ is the zero point energy difference between major $\mathrm{OC}^{32} \mathrm{~S}$ and a given isotopologue. $\triangle \mathrm{ZPE}$ calculated are $3.524,6.852$, and $13.026 \mathrm{~cm}^{-1}$ for $\mathrm{OC}^{33} \mathrm{~S}, \mathrm{OC}^{34} \mathrm{~S}$, and $\mathrm{OC}^{36} \mathrm{~S}$, respectively.

The OCS absorption spectrum of Molina et al. (1981) is shown in Fig. 2b. That is taken as ${ }^{32}$ OCS and is approximated by a function of the form:

${ }^{32} \sigma=\exp \left(\sum_{n=0}^{6} A_{n} \lambda^{n}\right)$

where various $A$ are constants. Equations (5) and (6) are used to estimate the ratios of isotopologue specific cross sections (e.g. ${ }^{33} \sigma /^{32} \sigma,{ }^{34} \sigma /^{\beta 2} \sigma$, and ${ }^{36} \sigma \beta^{32} \sigma$ ). Equation (4) is integrated to the wavelength range, from 190 to $280 \mathrm{~nm}$, and to the photochemical cell length (i.e. $z=0$ to $30 \mathrm{~cm}$ ) to estimate $\varepsilon_{1}$ for the experimental conditions by Eq. (7) (Miller et al., 2005). Results are shown in Table 3.

$\varepsilon_{1}=\frac{J^{\prime}}{J}-1$

where $J$ and $J^{\prime}$ are the photodissociation rate constant of ${ }^{32} \mathrm{~S}$ and those of substituted isotopologues ${ }^{33} \mathrm{~S},{ }^{34} \mathrm{~S}$, and ${ }^{36} \mathrm{~S}$, respectively.

The magnitude (and sign) of the expected isotope effects depends upon the irradiance spectrum determined by the light source and window material. The wavelength dependence for the isotope effects are intensively studied for nitrous oxide photolysis (Kaiser et al., 2003). This is because the ZPE-shift method suggests the sign of the isotope effect changes at the maximum absorption at $222 \mathrm{~nm}$ (Fig. 2c). The estimated fractionation is positive (product ${ }^{34} \mathrm{~S}$-enriched) for photolysis with $\lambda<222 \mathrm{~nm}$ and negative (product ${ }^{34} \mathrm{~S}$-depleted) for photolysis with $\lambda>222 \mathrm{~nm}$. The photon flux $\left(F_{0}\right)$ for the Xe arc lamp was given by the manufacture's datasheet and was corrected for measured transmittance for the window material. Calculated total photolysis rate constant (i.e. ${ }^{32} J+{ }^{33} J+{ }^{34} J+{ }^{36} J$ ) is shown in Fig. $2 d$ at varying total pressures of OCS. The rate constant shows maximum at $226 \mathrm{~nm}$ at total pressure of OCS of $2.7 \mathrm{mbar}$. This is slightly higher than the maximum OCS cross section at $222 \mathrm{~nm}$ because of the increasing photon flux from the Xe arc lamp with increasing wavelength (Fig. 2a). The ${ }^{34} \varepsilon_{1}$ values calculated by ZPE-shift method are $-2.2 \%$ at
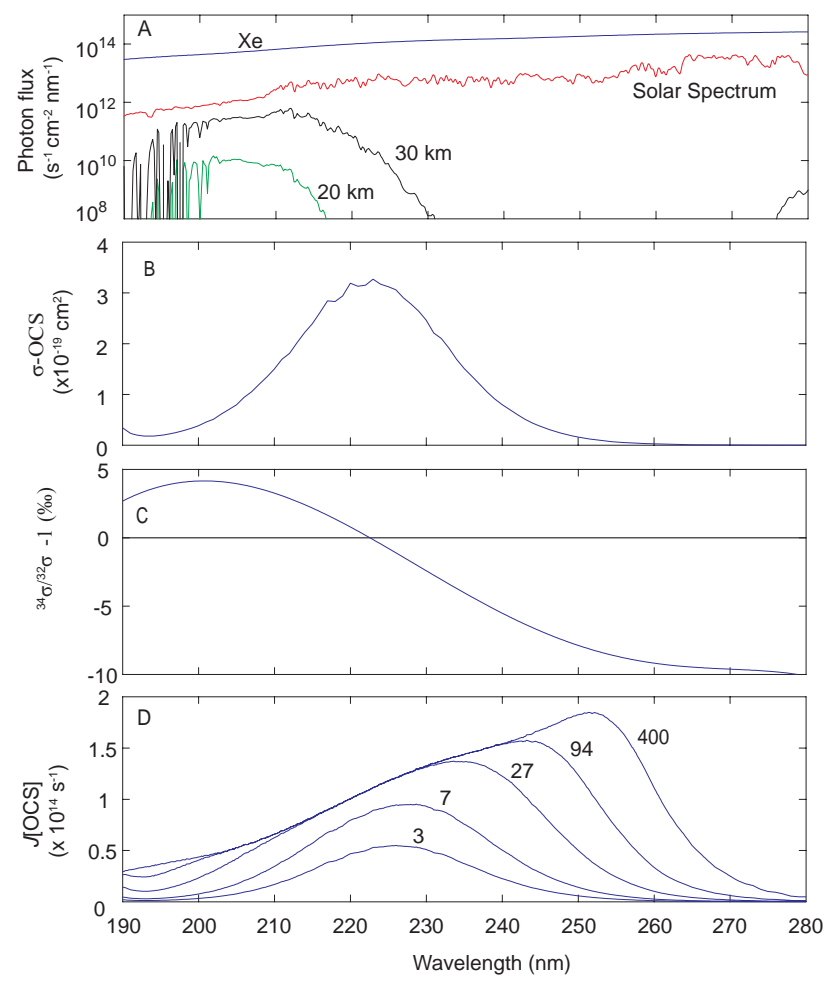

Fig. 2. Input parameters for the models for isotope fractionation. (A) Comparison of photon flux of Xe arc lamp and solar spectrum (Rottman et al., 2006). (B) OCS cross section from Molina et al. (1981). (C) ${ }^{34} \sigma /{ }^{32} \sigma-1$ estimated from ZPE-shift method. (D) Photolysis rate as a function of OCS pressure (numbers in diagram in mbar). Actinic flux at different altitudes is calculated similarly to Farquhar et al. (2001) for a solar zenith angle of $30^{\circ}$. Xe lamp used in this study has higher photon flux compared to solar spectrum by about a factor of 20 for the region between 190 and $270 \mathrm{~nm}$.

OCS gas pressure of $26.7 \mathrm{mbar}$ and $-4.1 \%$ at OCS gas pressure of $400 \mathrm{mbar}$, both at wavelength region of $190-280 \mathrm{~nm}$, largely consistent with our results of small $(<10 \%$ o) isotope effect during the photolysis of OCS (Table 3). The isotope effect is a weak function of the pressure because a part of UV absorption saturates at higher OCS pressures such that maximum absorption shifts to longer wavelength (Fig. 2d). The ratios of $\varepsilon_{1}$ values are 0.514 and 1.90 for ${ }^{33} \varepsilon_{1} /{ }^{34} \varepsilon_{1}$ and ${ }^{36} \varepsilon_{1}{ }^{\beta 4} \varepsilon_{1}$, respectively, which according to Eq. (2), approximately equal to $0.517 \pm 0.021$ and $1.851 \pm 0.118$ for $\ln \left(\delta^{33} \mathrm{~S}+1\right) / \ln \left(\delta^{34} \mathrm{~S}+1\right)$ and $\ln \left(\delta^{36} \mathrm{~S}+1\right) / \ln \left(\delta^{34} \mathrm{~S}+1\right)$ of product $\mathrm{S}$ for the 8 basic runs, respectively. The massdependence for the ZPE-shift method is expected since estimated ZPE shift is inherently mass-dependent.

The ZPE-shift method predicts a large negative isotope effect of $-10.1 \%$ of ${ }^{34} \varepsilon_{1}$ with irradiance at $280 \mathrm{~nm}$ (Fig. 2c). This is consistent with the relatively large magnitude fractionation measured for photolysis with $\lambda>285 \mathrm{~nm}$ compared to full spectrum experiments. Using the ZPE-shift method to estimate isotope effect with $\lambda>280 \mathrm{~nm}$ is not plausible 
Table 3. Isotope effects for OCS photolysis by Xe lamp as a function of OCS pressure estimated from the ZPE-shift method.

\begin{tabular}{lrrrrr}
\hline Pressure (mbar) & ${ }^{33} \varepsilon_{1}$ & ${ }^{34} \varepsilon_{1}$ & ${ }^{36} \varepsilon_{1}$ & ${ }^{33} \theta$ & ${ }^{36} \theta$ \\
\hline 2.7 & -0.70 & -1.35 & -2.56 & 0.5135 & 1.901 \\
13.3 & -0.93 & -1.80 & -3.41 & 0.5139 & 1.899 \\
26.7 & -1.12 & -2.19 & -4.15 & 0.5139 & 1.899 \\
400 & -2.09 & -4.06 & -7.69 & 0.5139 & 1.898 \\
\hline
\end{tabular}

because the estimation requires accurate determination of absorption spectrum at $\lambda>280 \mathrm{~nm}$.

Danielache et al. (2009) reported isotopologue specific cross sections estimated from wavepacket dynamics calculation. Predicted isotope effect $\left({ }^{34} \varepsilon_{1}\right)$ is consistent with that of the ZPE-shift method at low energy side $(\lambda>\approx 220 \mathrm{~nm})$ but differs significantly at high energy side of the spectrum $(\lambda<\approx 220 \mathrm{~nm})$. Danielache et al. (2009) estimated ${ }^{34} \varepsilon_{1}$ of $+4.9 \%$ for the OCS photolysis at $190-250 \mathrm{~nm}$. The predicted isotope effect $\left({ }^{34} \varepsilon_{1}\right)$ is $+4.2 \%$ o for the light source used in this experiments. If one applies $+4.2 \%$ or photolysis isotope effect $\left({ }^{34} \varepsilon_{1}\right)$ and $-6.8 \%$ ofor ${ }^{34} \varepsilon$, isotope effect associated with sulfur abstraction reaction $\left({ }^{34} \varepsilon_{2}\right)$ is estimated to be $-17.8 \%$. This magnitude of the isotope effect agrees well with what is estimated $(-18.9 \%$ ) for one of the transition states (TS1).

\subsection{Multiple sulfur isotope effect}

Bhattacharya et al. (2000) reported a large magnitude nonmass-dependent isotope fractionation among triple oxygen isotope system $\left({ }^{16} \mathrm{O}_{-}{ }^{17} \mathrm{O}-{ }^{18} \mathrm{O}\right)$ during photolysis of carbon dioxide at $185 \mathrm{~nm}$. They attributed near resonant vibronic coupling between singlet and triplet states to be the source of non-mass-dependent fractionation during the photolysis. The anomalous isotope effect was only observed for spin forbidden dissociation process; the isotope effect follows conventional mass-dependence for the photolysis with $\lambda<160 \mathrm{~nm}$, where $\mathrm{CO}_{2}$ photodissociates without spin violation. One may expect similar non-mass-dependent isotope effect in sulfur isotope system for the spin-forbidden photolysis process for OCS (Lyons, 2009).

The photolysis of OCS produces predominantly $S\left({ }^{1} \mathrm{D}\right)$ without spin violation. Because dissociation threshold through $S\left({ }^{1} \mathrm{D}\right)$ channel is about $285 \mathrm{~nm}$, the experiments with $\lambda>285 \mathrm{~nm}$ produces $\mathrm{S}\left({ }^{3} \mathrm{P}\right)$ exclusively through a spin-forbidden process much like the $\mathrm{CO}_{2}$ photolysis with $\lambda>167 \mathrm{~nm}$. The OCS photolysis with $\lambda>285 \mathrm{~nm}$, however, is largely mass-dependent, suggesting that OCS photolysis through $\mathrm{S}\left({ }^{3} \mathrm{P}\right)$ channel is mass-dependent. A slight increase in ${ }^{34}$ S-depletion $(-9.5 \%$ ) for photolysis with $\lambda>285 \mathrm{~nm}$ compared to the full spectrum is measured. This is consistent with a simple ZPE-shift method (Miller and Yung, 2000), which is inherently mass-dependent.
The observed triple isotope coefficients $\ln \left(\delta^{33} \mathrm{~S}+\right.$ $1) / \ln \left(\delta^{34} S+1\right)$ and $\ln \left(\delta^{36} S+1\right) / \ln \left(\delta^{34} S+1\right)$ are denoted as ${ }^{33} \gamma$ and ${ }^{36} \gamma$, respectively (Ono et al., 2006). ${ }^{33} \gamma$ and ${ }^{36} \gamma$ for all the runs in our study are 0.534 and 1.980 , respectively, and are statistically different from what are expected for canonical mass dependence of 0.515 and 1.90 for ${ }^{33} \theta$ and ${ }^{36} \theta$ (e.g. Hulston and Thode, 1965; Otake et al., 2008). It has been shown that closed system effect may make the observed triple isotope coefficients slightly different from that intrinsic to the reaction (i.e. ${ }^{33} \gamma \neq{ }^{33} \theta$ ) (e.g. Kaiser et al., 2004; Ono et al., 2006). Such an effect is scaled to the magnitude of the isotope fractionation $\left({ }^{34} \varepsilon\right)$, and is expected to be of minor importance for the range of ${ }^{34} \varepsilon$ values observed in our experiments. The isotopic composition of the reactant evolves following the relationship ${ }^{33} \gamma=\left({ }^{34} \alpha^{33 \theta}-1\right) /\left({ }^{34} \alpha-1\right)$ (Ono et al., 2006). ${ }^{33} \gamma$ approaches ${ }^{33} \theta$ when ${ }^{34} \alpha$ approaches unity (Ono et al., 2006). For example, for residual OCS in the 5 runs of pure OCS photolysis with $\lambda>200 \mathrm{~nm}$, the linear regression yields $\ln \left(\delta^{33} \mathrm{~S}+1\right) / \ln \left(\delta^{34} \mathrm{~S}+1\right)=0.557 \pm 0.010$. With this ${ }^{33} \gamma$ value, according to Eq. (14) of Ono et al. (2006), ${ }^{33} \theta$ of $0.556 \pm 0.010$ for the reactants in these 5 runs is derived for ${ }^{34} \alpha=0.9932$ (i.e. ${ }^{34} \varepsilon=-6.8 \%$ ). This simple analysis shows the minor difference between ${ }^{33} \gamma$ and ${ }^{33} \theta$ for our experiments, confirms non-canonical multiplesulfur isotope relationship and suggests potential non-massdependent isotope effects during the OCS photolysis. In addition, ${ }^{33} \gamma$ of $0.534 \pm 0.005$ is out of the range for massdependent fractionation from 0.5007 (kinetic fractionation) to 0.5159 (equilibrium fractionation) (Kaiser and Röckmann, 2008). However, ${ }^{36} \gamma$ of $1.980 \pm 0.021$ is within the range for mass-dependent fractionation from 1.8906 (equilibrium fractionation) to 2.0019 (kinetic fractionation) (Kaiser and Röckmann, 2008).

This potential non-mass-dependent fractionation may be related to shorter wavelength $(\lambda<220 \mathrm{~nm})$ rather than longer wavelength $(\lambda>285 \mathrm{~nm})$ photolysis. Danielache et al. (2009) suggested significant sulfur isotope effects at high energy side of the spectrum $(\lambda<220 \mathrm{~nm})$. They also suggested that forbidden transition from the lowest excited state $\left({ }^{1} \Delta\right)$ and ground state $\left({ }^{1} \Sigma^{+}\right)$may be allowed in the bend geometry of excited $2^{1} \mathrm{~A}^{\prime}-1^{1} \mathrm{~A}^{\prime}$ states via vibronic coupling. Such vibronic coupling may lead to non-mass-dependent isotope effects during OCS photolysis process.

Other potential sources of non-mass-dependent fractionation include isotope self-shielding of the product $S_{2}$ and symmetry-dependent fractionation during $\mathrm{S}+\mathrm{S}_{2}$ recombination reaction, analogue to ozone recombination reaction. The $\mathrm{S}_{2}$ has structured and characteristic absorptions at $280 \mathrm{~nm}$ (Herman and Herman, 1963). However, such absorption bands were not observed during our experiments, suggesting $\mathrm{S}_{2}$ isotope self-shielding is unlikely under our experimental condition. Thiozone $\left(S_{3}\right)$ reaction may produce ozone like non-mass-dependent fractionation (Francisco et al., 2005) but the contribution of such reaction is unknown. 


\subsection{Implications to stratospheric sulfur aerosol (SSA)}

Castleman et al. (1974) suggested the $\delta^{34} \mathrm{~S}$ of background SSA to be $+2.6 \%$. The $\delta^{34} \mathrm{~S}$ value of the tropospheric OCS has not been measured but was estimated to be $+11 \%$ o (Newman et al., 1991). The photolysis isotope effect of $-8.4 \%$ o would be expected if the OCS photolysis is the main source of sulfur in SSA. Based upon large ${ }^{34} \varepsilon$ for photolysis of OCS of larger than $67 \%$, Leung et al. (2002) and Colussi et al. (2004) concluded that OCS does not contribute significantly to the SSA or the large positive isotope effect is cancelled out by other sulfur source with highly negative $\delta^{34}$ S. Our experimental results demonstrate the OCS photolysis $\left({ }^{34} \varepsilon_{1}\right)$ is unlikely to produce large $(>10 \%)$ isotope effects, and thus, OCS can be a major contributor for SSA in volcanic quiescent periods. Hattori et al. (2011) estimated ${ }^{34} \varepsilon_{1}$ to be $(1.1 \pm 4.2) \%$ o for OCS photolysis at $20 \mathrm{~km}$ altitude by the measurement of OCS spectra. The estimated small fractionation is consistent with the result of this study.

Ueno et al. (2009) suggested OCS was important greenhouse gas in the early Earth, compensating the Earth's radiation budget under low solar luminosity. If this were the case, OCS is expected to contribute significant $\mathrm{S}$ production during the Archean era because OCS absorbs photons to shield $\mathrm{SO}_{2}$ but it dissociates at quantum efficiency close to unity. This study confirms that the isotope effect during the OCS photolysis and following $\mathrm{S}$ abstraction reactions are largely mass-dependent.

In order to further constrain the isotope effect for the OCS photolysis in the stratosphere, future laboratory experiments should focus on the photolysis with $\lambda$ of about $200 \mathrm{~nm}$ because this is the window of UV that becomes available at above $20 \mathrm{~km}$ altitude (Minschwaner et al., 1993; DeMore et al., 1997) and where most OCS photolysis is occurring (Colussi et al., 2004). The photolysis experiments with $\lambda$ of about $200 \mathrm{~nm}$ may also provide experimental confirmation for the results of Danielache et al. (2009) about the deviation of isotope effect from the ZPE-shift method, and potential non-mass-dependent isotope effects in the sulfur isotope system. Our experimental results, however, have direct inference on the long wavelength $(\lambda>270 \mathrm{~nm})$ OCS photolysis that would be potentially important as the fate of tropospheric OCS (Turco et al., 1981).

\section{Conclusions}

Laboratory photolysis of carbonyl sulfide produced elemental sulfur depleted in heavy isotopes by $-6.8 \%$ o for the ratio ${ }^{34} \mathrm{~S} /{ }^{32} \mathrm{~S}$ relative to initial OCS. Because OCS photolysis reaction is followed by sulfur abstraction reaction $\left(\mathrm{OCS}+\mathrm{S} \rightarrow \mathrm{CO}+\mathrm{S}_{2}\right)$, the measured isotope effect is an average of the effects produced by photolysis and abstraction reactions. The isotope effect for abstraction reaction is estimated by using transition state theory to be $-18.9 \%$ (TS1) and $-3.1 \%$ (TS2). Therefore, the isotope effect due to photolysis under experimental conditions is constrained to be -10.5 to $+5.3 \%$. A relatively small $(<10 \%$ o $)$ isotope effect is consistent with the ZPE-shift method of Miller and Yung (2000) as well as the result of recent wavepacket dynamic calculation by Danielache et al. (2009). The sulfur isotope constraints on the contribution of OCS to the stratospheric sulfate aerosol layer need to be reevaluated.

The observed triple isotope coefficients for the 12 experiments are $0.534 \pm 0.005$ and $1.980 \pm 0.021$ for $\ln \left(\delta^{33} \mathrm{~S}+1\right) / \ln \left(\delta^{34} \mathrm{~S}+1\right)$ and $\ln \left(\delta^{36} \mathrm{~S}+1\right) / \ln \left(\delta^{34} \mathrm{~S}+1\right)$, respectively. These values are statistically different from the canonical values of 0.515 and 1.90 , suggesting potential nonmass-dependent isotope effects during OCS photolysis. Further experiments are underway to test if photolysis with $\lambda$ of about $200 \mathrm{~nm}$, relevant range for stratospheric OCS photolysis, would produce larger and non-mass-dependent isotope effects.

This study demonstrates that simple laboratory photochemical experiments, theoretical quantum physics, and spectroscopic experiments (i.e. absorption cross section measurements for pure isotopologues) are complimentary to each other, and often required to untangle isotope effects in complex photochemical processes.

\section{Supplementary material related to this article is available online at: http://www.atmos-chem-phys.net/11/10283/2011/ acp-11-10283-2011-supplement.pdf.}

Acknowledgements. William J. Olszewski contributed to the construction of sulfur fluorination line, the automated purification line for $\mathrm{SF}_{6}$ and the associated control program. Sebastian Danielache calculated $\varepsilon$ values based on theoretical spectra. The authors have heartfelt gratitude to them. The authors would also like to thank Jan Kaiser, Matthew S. Johnson, Joel Savarino, and Sebastian Danielache for helpful suggestions. This project was supported by the NASA exobiology program, Grant No. NNX10AR85G.

Edited by: J. Kaiser

\section{References}

Barkley, M. P., Palmer, P. E., Boone, C. D., and Bernath, P. F.: Global distributions of carbonyl sulfide in the upper troposphere and stratosphere, Geophys. Res. Lett., 35, L14810, doi:10.1029/2008GL034270, 2008.

Baroni, M., Thiemens, M. H., Delmas, R. J., and Savarino, J.: Mass-independent sulfur isotopic compositions in stratospheric volcanic eruptions, Science, 315, 84-87, 2007.

Basco, N. and Pearson, A. E.: Reactions of sulphur atoms in presence of carbon disulphide, carbonyl sulphide and nitric oxide, Trans. Faraday Soc., 63, 2684-2694, 1967.

Bhattacharya, S. K., Savarino, J., and Thiemens, M. H.: A new class of oxygen isotopic fractionation in photodissociation of car- 
bon dioxide: Potential implications for atmospheres of Mars and Earth, Geophys. Res. Lett., 27, 1459-1462, 2000.

Bigeleisen, J. and Mayer, M. G.: Calculation of equilibrium constants for isotopic exchange reactions, J. Chem. Phys., 15, 261267, 1947.

Blake, N. J., Campbell, E., Vay, S. A., Fuelberg, H. E., Huey, L. G., Sachse, G., Meinardi, S., Beyersdorf, A., Baker, A., Barletta, B., Midyett, J., Doezema, L., Kamboures, M., McAdams, J., Novak, B., Rowland, F. S., and Blake, D. R.: Carbonyl sulfide (OCS): Large-scale distributions over North America during INTEX-NA and relationship to $\mathrm{CO}_{2}$, J. Geophys. Res., 113, D09S90, doi:10.1029/2007JD009163, 2008.

Breckenridge, W. H. and Taube, H.: Some reactions of ground-state $\left({ }^{3} \mathrm{P}\right)$ and electronically excited $\left({ }^{1} \mathrm{D}\right)$ sulfur atoms, J. Chem. Phys., 53, 1750-1767, 1970.

Canfield, D. E., Raiswell, R., Westrich, J. T., Reaves, C. M., and Berner, R. A.: The use of chromium reduction in the analysis of reduced inorganic sulfur in sediments and shales, Chem. Geol., 54, 149-155, 1986.

Castleman, A. W., Munkelwitz, H. R., and Manowitz, B.: Contribution of volcanic sulphur compounds to the stratospheric aerosol layer, Nature, 244, 345-346, 1973.

Castleman, A. W., Munkelwitz, H. R., and Manowitz, B.: Isotopic studies of the sulfur component of the stratospheric aerosol layer, Tellus, 26, 222-234, 1974.

Chin, M. and Davis, D. D.: A reanalysis of carbonyl sulfide as a source of stratospheric background sulfur aerosol, J. Geophys. Res., 100, 8993-9005, 1995.

Colman, J. J., Xu, X. P., and Thiemens, M. H.: Photopolymerization and mass-independent sulfur isotope fractionations in carbon disulfide, Science, 273, 774-776, 1996.

Colussi, A. J., Leung, F.-Y. T., and Hoffmann, M. R.: Electronic spectra of carbonyl sulfide sulfur isotopologues, Environ. Chem., 1, 44-48, 2004.

Crutzen, P. J.: The possible importance of CSO for the sulfate aerosol layer of the Stratosphere, Geophys. Res. Lett., 3, 73-76, 1976

Danielache, S. O., Johnson, M. S., Nanbu, S., Grage, M. M.-L., McLinden, C., and Yoshida, N.: Ab initio study of sulfur isotope fractionation in the reaction of OCS with $\mathrm{OH}$, Chem. Phys. Lett., 450, 214-220, 2008

Danielache, S. O., Nanbu, S., Eskebjerg, C., Johnson, M. S., and Yoshida, N.: Carbonyl sulfide isotopologues: ultraviolet absorption cross sections and stratospheric photolysis, J. Chem. Phys., 131, 024307, doi:10.1063/1.3156314, 2009.

DeMore, W. B., Sanders, S. P., Golden, D. M., Hampson, R. F., Kurylo, M. J., Howard, C. J., Ravishankara, A. R., Kolb, C. E., and Molina, M. J.: Chemical kinetics and photochemical data for use in stratospheric modeling, JPL, evaluation no. 12, California Institute of Technology, Pasadena, California, 1997.

Du, S., Francisco, J. S., Shepler, B. C., and Peterson, K. A.: Determination of the rate constant for sulfur recombination by quasiclassical trajectory calculations, J. Chem. Phys., 128, 204306, doi:10.1063/1.2919569, 2008.

Farquhar, J., Bao, H., and Thiemens, M. H.: Atmospheric influence of the Earth's earliest sulfur cycle, Science, 289, 756-758, 2000.

Farquhar, J., Savarino, J., Airieau, S., and Thiemens, M. H.: Observation of wavelength-sensitive mass-independent sulfur isotope effects during $\mathrm{SO}_{2}$ photolysis: Applications to the early atmo- sphere, J. Geophys. Res., 12, 32829-32839, 2001.

Farwell, S. O., MacTaggart, D. L., Chathan, W., Everson, D. O., Samaranayake, K., and Lim, Y. T.: Airborne measurements of total sulfur gases during NASA Global Tropospheric Experiment/Chemical Instrumentation Test and Evaluation 3, J. Geophys. Res., 100, 7223-7234, 1995.

Francisco, J. S., Lyons, J. R., Williams, I. H.: High-level ab initio studies of the structure, vibrational spectra, and energetics of $\mathrm{S}_{3}$, J. Chem. Phys., 123, 054302, doi:10.1063/1.1979474, 2005.

Hattori, S., Danielache, S. O., Johnson, M. S., Schmidt, J. A., Kjaergaard, H. G., Toyoda, S., Ueno, Y., and Yoshida, N.: Ultraviolet absorption cross sections of carbonyl sulfide isotopologues $\mathrm{OC}^{32} \mathrm{~S}, \mathrm{OC}^{33} \mathrm{~S}, \mathrm{OC}^{34} \mathrm{~S}$ and $\mathrm{O}^{13} \mathrm{CS}$ : isotopic fractionation in photolysis and atmospheric implications, Atmos. Chem. Phys., 11, 10293-10303, doi:10.5194/acp-11-10293-2011, 2011.

Herman, L. and Herman, R.: Perturbations in the $\mathrm{S}_{2}$ spectrum, Nature, 4863, 677-677, 1963 .

Hulston, J. R. and Thode, H. G.: Variations in the $S^{33}, S^{34}$, and $S^{36}$ contents of meteorites and their relation to chemical and nuclear effects, J. Geophys. Res., 70, 3475-3484, 1965.

Junge, C. E., Chagnon, C. W., and Manson, J. E.: Stratospheric aerosols, J. Meteorology, 18, 81-108, 1961.

Kaiser, J. and Röckmann, T.: Correction of mass-spectrometric isotope ratio measurements for isobaric isotopologues of $\mathrm{O}_{2}$, $\mathrm{CO}, \mathrm{CO}_{2}, \mathrm{~N}_{2} \mathrm{O}$ and $\mathrm{SO}_{2}$, Rapid Commun. Mass Spectrom., 22, 3997-4008, 2008.

Kaiser, J., Röckmann, T., Brenninkmeijer, C. A. M., and Crutzen, P. J.: Wavelength dependence of isotope fractionation in $\mathrm{N}_{2} \mathrm{O}$ photolysis, Atmos. Chem. Phys., 3, 303-313, doi:10.5194/acp3-303-2003, 2003.

Kaiser, J., Röckmann, T., and Brenninkmeijer, C. A. M.: Contribution of mass-dependent fractionation to the oxygen isotope anomaly of atmospheric nitrous oxide, J. Geophys. Res., 109, D03305, doi:10.1029/2003JD004088, 2004.

Khalil, M. A. K. and Rasmussen, R. A.: Global sources, lifetimes and mass balances of carbonyl sulfide (OCS) and carbon disulfide $\left(\mathrm{CS}_{2}\right)$ in the Earth's atmosphere, Atmos. Environ., 18, 18051813, 1984.

Leung, F.-Y. T., Colussi, A. J., Hoffmann, M. R., and Toon, G. C.: Isotopic Fractionation of carbonyl sulfide in the atmosphere: implications for the source of background stratospheric sulfate aerosol, Geophys. Res. Lett., 29, 1474, doi:10.1029/2001GL013955, 2002.

Lu, C.-W., Wu, Y.-J., Lee, Y.-P., Zhu, R. S., and Lin, M. C.: Experimental and theoretical investigation of rate coefficients of the reaction $\mathrm{S}\left({ }^{3} \mathrm{P}\right)+$ OCS in the temperature range of 298-985 K, J. Chem. Phys., 125, 164329, doi:10.1063/1.2357739, 2006

Luz, B. and Barkan, E.: The isotope ratios ${ }^{17} \mathrm{O} /{ }^{16} \mathrm{O}$ and ${ }^{18} \mathrm{O} /{ }^{16} \mathrm{O}$ in molecular oxygen and their significance in biogeochemistry, Geochim. Cosmochim. Acta, 69, 1099-1110, 2005.

Lyons, J. R.: Atmospherically-derived mass-independent sulfur isotope signatures, and incorporation into sediments, Chem. Geol., 267, Sp. Iss. SI, 164-174, 2009.

Mariotti, A., Germon, J. C., Hubert, P., Kaiser, P., Letolle, R., Tardieux, A., and Tardieux, P.: Experimental determination of nitrogen kinetic isotope fractionation: some principles; illustration for the denitrification and nitrification processes, Pl. Soil, 62 , 413-430, 1981.

Masukidi, L. S., Lahaye, J. G., and Fayt, A.: Intracavity CO and 
$\mathrm{CO}_{2}$ laser Stark spectroscopy of the isotopomers of carbonyl sulfide, J. Mol. Spectrosc., 154, 137-162, 1992.

Miller, C. E. and Yung, Y. L.: Photo-induced isotopic fractionation, J. Geophys. Res., 105, 29039-29051, 2000.

Miller, C. E., Onorato, R. M., Liang, M.-C., and Yung, Y. L.: Extraordinary isotopic fractionation in ozone photolysis, Geophys. Res. Lett., 32, L14814, doi:10.1029/2005GL023160, 2005.

Minschwaner, K., Salawitch, R. J., and McElroy, M. B.: Absorption of solar radiation by $\mathrm{O}_{2}$ : implications for $\mathrm{O}_{3}$ and lifetimes of $\mathrm{N}_{2} \mathrm{O}, \mathrm{CFCl}_{3}$, and $\mathrm{CF}_{2} \mathrm{Cl}_{2}$, J. Geophys. Res., 98, 10543-10561, 1993.

Molina, L. T., Lamb, J. J., and Molina, M. J.: Temperaturedependent UV absorption cross-sections for carbonyl sulfide, Geophys. Res. Lett., 8, 1008-1011, 1981.

Newman, L., Krouse, H. R., and Grinenko, V. A.: Sulphur isotope variations in the atmosphere, in Stable Isotopes: Natural and Anthropogenic sulphur in the Environment, edited by $\mathrm{H}$. R. Krouse and V. A. Grinenko, 133-176, Scientific Committee On Problems of Environment (SCOPE), available at: http: //www.icsu-scope.org/downloadpubs/scope43/index.html, 1991.

Ohmoto, H. and Lasaga, A. C.: Kinetics of reactions between aqueous sulfates and sulfides in hydrothermal systems, Geochim. Cosmochim. Acta, 46, 1727-1745, 1982.

Okabe, H.: Photochemistry of small molecules, John Wiley, New York, 215-217, 1978.

Ono, S., Eigenbrode, J. L., Pavlov, A. A., Kharecha, P., Rumble, D., Kasting, J. F., and Freeman, K. H.: New insights into Archean sulfur cycle from mass-independent sulfur isotope records from the Hamersley Basin, Australia, Earth Planet. Sci. Lett., 213, 1530, 2003.

Ono, S., Wing, B., Johnston, D., Rumble, D., and Farquhar, J.: Mass-dependent fractionation of quadruple stable sulfur isotope system as a new tracer of sulfur biogeochemical cycles, Geochim. Cosmochim. Acta, 70, 2238-2252, 2006.

Otake, T., Lasaga, A. C., and Ohmoto, H.: Ab initio calculations for equilibrium fractionations in multiple sulfur isotope systems, Chem. Geol., 249, 357-376, 2008.

Pandis, S. N., Wexler, A. S., and Seinfeld, J. H.: Dynamics of tropospheric aerosols, J. Phys. Chem., 99, 9646-9659, 1995.

Pitari, G., Mancini, E., Rizi, V., and Shindell, D. T.: Impact of future climate and emission changes on stratospheric aerosols and ozone, J. Atmos. Sci., 59, 414-440, 2002.

Pyle, D. M., Beattie, P. D., and Bluth, G. J. S.: Sulphur emissions to the stratosphere from explosive volcanic eruptions, Bull. Volcanol., 57, 663-671, 1996.

Robock, A., Oman, L., and Stenchikov, G. L.: Regional climate responses to geoengineering with tropical and Arctic $\mathrm{SO}_{2}$ injections, J. Geophys. Res., 113, D16101, doi:10.1029/2008JD010050, 2008.

Rottman, G. J., Woods, T. N., and McClintock, W.: SORCE solar UV irradiance results, Adv. Space Res., 37, Sp. Iss. 201-208, 2006.
Rudolph, R. N. and Inn, E. C. Y.: OCS photolysis and absorption in the 200- to 300- nm region, J. Geophys. Res., 86, 9891-9894, doi:10.1029/JC086iC10p09891, 1981.

Savarino, J., Romero, A., Cole-Dai, J., Bekki, S., and Thiemens, M. H.: UV induced mass-independent sulfur isotope fractionation in stratospheric volcanic sulfate, Geophys. Res. Lett., 30, 2131, doi:10.1029/2003GL018134, 2003.

Sidhu, K. S., Csizmadia, I. G., Strausz, O. P., and Gunning, H. E.: The reactions of sulfur atoms. VII. The ultraviolet spectrum, the photolysis, and the mercury sensitization of carbonyl sulfide, J. Amer. Chem. Soc., 88, 2412-2417, 1966.

SPARC: SPARC Assessment of Stratospheric Aerosol Properties (ASAP), edited by: Thomason, L. and Peter, T., Tech. Rep. WMO-TD No. 1295, WCRP Series Report No. 124, SPARC Report No. 4, Berrieres le Buisson Cedex, 2006.

Suzuki, T., Katayanagi, H., Nanbu, S., and Aoyagi, M.: Nonadiabatic bending dissociation in 16 valence electron system OCS, J. Chem. Phys., 109, 5778-5794, 1998.

Tanaka, N., Xiao, Y. T., and Lasaga, A. C.: Ab initio study on carbon Kinetic Isotope Effect (KIE) in the reaction of $\mathrm{CH}_{4}+\mathrm{Cl}$, J. Atmos. Chem., 23, 37-49, 1996.

Turco, R. P., Whitten, R. C., Toon, O. B., Pollack, J. B., and Hamill, P.: OCS, stratospheric aerosols and climate, Nature, 283, 283286, 1980.

Turco, R. P., Cicerone, R. J., Inn, E. C. Y., and Capone, L. A.: Long wavelength carbonyl sulfide photo-dissociation, J. Geophys. Res., 86, 5373-5377, 1981.

Ueno, Y., Johnson, M. S., Danielache, S. O., Eskebjerg, C., Pandey, A., and Yoshida, N.: Geological sulfur isotopes indicate elevated OCS in the Archean atmosphere, solving faint young sun paradox, P. Natl. Acad. Sci. USA, 106, 14784-14789, 2009.

Van Hook, W. A.: Kinetic isotope effect: Introduction and discussion of the theory, in C.J. Collins and N.S. Bowman (eds.) Isotope effect in chemical reactions, Van Nostrand Reinhold CO, New York, 1970.

von Hessberg, P., Kaiser, J., Enghoff, M. B., McLinden, C. A., Sorensen, S. L., Röckmann, T., and Johnson, M. S.: Ultra-violet absorption cross sections of isotopically substituted nitrous oxide species: ${ }^{14} \mathrm{~N}^{14} \mathrm{NO},{ }^{15} \mathrm{~N}^{14} \mathrm{NO},{ }^{14} \mathrm{~N}^{15} \mathrm{NO}$ and ${ }^{15} \mathrm{~N}^{15} \mathrm{NO}$, Atmos. Chem. Phys., 4, 1237-1253, doi:10.5194/acp-4-1237-2004, 2004.

Wiebe, H. A., Knight, A. R., Strausz, O. P., and Gunning, H. E.: The reactions of sulfur atoms. V. Further studies on the reactions with olefins, J. Amer. Chem. Soc., 87, 1443-1449, 1964.

Zhao, Z., Stickel, R. E., and Wine, P. H.: Quantum yield of carbon monoxide production in the $248 \mathrm{~nm}$ photodissociation of carbonyl sulfide (OCS), Geophys. Res. Lett., 22, 615-618, 1995.

Zmolek, P., Xu, X. P., and Jackson, T.: Large mass independent sulfur isotope fractionations during the photopolymerization of $\left(\mathrm{CS}_{2}\right)-\mathrm{C}-12$ and $\left(\mathrm{CS}_{2}\right)-\mathrm{C}-13$, J. Phys. Chem. A, 103, 2477-2480, 1999. 